\title{
ГЕНЕТИЧЕСКИ КОДИРУЕМЫЙ БИОСЕНСОР RОКАТЕ ДЛЯ РЕГИСТРАЦИИ РЕДОКС-СОСТОЯНИЯ ПУЛА ГЛУТАТИОНА
}

\author{
А. Г. Шохина ${ }^{1}$, В. В. Белоусов ${ }^{1,2}$, Д. С. Билан ${ }^{1 凶}$
}

Институт биоорганической химии имени М. М. Шемякина и Ю. А. Овчинникова РАН, Москва, Россия

Научно-исследовательский институт трансляционной медицины,

Российский национальный исследовательский медицинский университет имени Н. И. Пирогова, Москва, Россия

\begin{abstract}
Генетически кодируемые биосенсоры на основе флуоресцентных белков представляют собой инструмент исследования ряда биологических процессов в живых системах в режиме реального времени. За последние годы было создано целое семейство биосенсоров, позволяющих визуализировать в живых клетках изменения редокс-состояния пула глутатиона. Целью настоящей работы была разработка нового биосенсора для регистрации соотношения 2GSH/GSSG на основе красного флуоресцентного белка mKate2. Для этого методом направленного мутагенеза в структуру флуоресцентного белка вносили пару аминокислотных остатков цистеина, которые при окислении окружающего пула глутатиона формируют дисульфидную связь, что приводит к изменению спектральных характеристик. Полученный биосенсор был протестирован in vitro на выделенном препарате белка, в частности, были исследованы спектральные характеристики, рН-чувствительность белка, окислительно-восстановительный потенциал. Кроме того, биосенсор, названный roKate, был протестирован в культуре живых клеток млекопитающих. Он отличается высокой яркостью и повышенной стабильностью сигнала при изменениях рН в физиологическом диапазоне. От других представителей данного семейства биосенсоров rоКате отличается необратимым изменением сигнала при окислении в клетках млекопитающих. Применение данного сенсора предпочтительно в экспериментах с наличием длительного промежутка времени между воздействием на биологическую систему и последующим анализом вызванного эффекта, например в условиях длительной пробоподготовки
\end{abstract}

Ключевые слова: генетически кодируемый флуоресцентный биосенсор, глутатион, соотношение 2GSH/GSSG, roKate

Финансирование: работа выполнена при поддержке гранта РФФИ мол_а_дк № 16-34-60175.

Информация о вкладе авторов: А. Г. Шохина проводила экспериментальную работу; В.В.Белоусов и Д. С. Билан руководили исследованиями, писали текст статьи.

$\bowtie$ Для корреспонденции: Дмитрий Сергеевич Билан

ул. Миклухо-Маклая, д. 16/10, г. Москва, 117997; d.s.bilan@gmail.com

Статья получена: 26.12.2018 Статья принята к печати: 02.03.2019 Опубликована онлайн: 14.03.2019

DOI: 10.24075 /vrgmu.2019.013

\section{A GENETICALLY ENCODED BIOSENSOR ROKATE FOR MONITORING THE REDOX STATE OF THE GLUTATHIONE POOL}

Shokhina $\mathrm{AG}^{1}$, Belousov $\mathrm{W}^{1,2}$, Bilan $\mathrm{DS}^{1} \bowtie$

Shemyakin-Ovchinnikov Institute of Bioorganic Chemistry, Moscow, Russia

2 Institute of Translatinoal Medicine,

Pirogov Russian National Research Medical University, Moscow, Russia

Genetically encoded fluorescent sensors are exploited to study a variety of biological processes in living organisms in real time. In recent years, a whole family of biosensors has been developed, serving to visualize changes in the glutathione redox state. The aim of our experiment was to design a biosensor based on the red fluorescent protein mKate2 for measuring the 2GSH/GSSG ratio. A pair of cysteine amino acid residues were introduced into the structure of the fluorescent protein using site-directed mutagenesis. These residues form a disulfide bridge when the surrounding glutathione pool is oxidized, affecting the spectral characteristics of the protein. Our biosensor, which we called roKate, was tested in vitro on an isolated protein. Specifically, we examined the spectral characteristics, pH and the redox potential of the sensor. Additionally, the performance of roKate was evaluated using the culture of living mammalian cells. The fluorescent signal emitted by the sensor was very bright and remarkably stable under $\mathrm{pH}$ conditions varying in the physiological range. Irreversibly oxidized in mammalian cells, roKate stands out from other members of this biosensor family. This biosensor should be preferred in the experiments when the time between the manipulations with the biological object and the subsequent analysis of the induced effect is substantial, as is the case with long sample preparation.

Keywords: genetically encoded fluorescent sensor, glutathione, 2GSH/GSSG ratio, roKate

Funding: this work was supported by the Russian Foundation for Basic Research (Project mol_a_dk No.16-34-60175).

Author contribution: Shokhina AG was responsible for the experimental part of the study. Belousov W and Bilan DS supervised the study and prepared this manuscript.

$\triangle$ Correspondence should be addressed: Dmitry S. Bilan

Miklouho-Maclay, 16/10, Moscow, 117997; d.s.bilan@gmail.com

Received: 26.12.2018 Accepted: 02.03.2019 Published online: 14.03.2019

DOI: $10.24075 /$ brsmu.2019.013

Изучение окислительно-восстановительных (далее редокс-) процессов представляет собой актуальное и интенсивно развивающееся направление в современных биомедицинских исследованиях. Соотношение восстановленной (GSH) и окисленной (GSSG) форм глутатиона представляет собой один из важнейших показателей редокс-статуса клеток. Глутатион по своей природе - трипептид (у-глутамилцистеинилглицин), концентрация которого в клетке может достигать высоких значений (до 10 мМ) [1]. Биологическая функция глутатиона обусловлена способностью его двух восстановленных молекул (2GSH) отдавать пару электронов молекуле акцептору. При этом глутатион переходит в окисленную форму с образованием дисульфида GSSG, который вновь может восстановиться с помощью фермента глутатионредуктазы (GR) [2]. GSH выполняет ключевую роль в реакциях восстановления перекисей липидов и пероксида водорода, которые возникают в клетках при окислительном стрессе. Структура и функции многих белков клетки зависят от обратимого формирования дисульфидных связей [3], восстановление которых происходит с помощью глутатиона. Таким образом, глутатион выполняет первостепенную роль в реакциях 
тиол-дисульфидного обмена клеток, а также вовлечен в глутатионилирование белков, что обусловливает его важную роль в процессах внутриклеточной редокссигнализации и фолдинга белков.

Многие патологические состояния вызваны нарушениями в системах, участвующих в регуляции внутриклеточного уровня глутатиона или его редокс-состояния (соотношения 2GSH/GSSG). Так, нарушение синтеза глутатиона, вызванное мутациями в генах, ответственных за синтез субъединиц у-глутамилцистеинсинтетазы, связано с развитием ряда заболеваний: сахарного диабета [4], астмы [5], шизофрении [6] и др. Нарушения в работе глутатионредуктазы, поддерживающей пул глутатиона в восстановленном состоянии, ассоциированы, например, с системной красной волчанкой [7] и некоторыми формами фавизма [8]. В опухолевых клетках активность этого фермента часто наоборот оказывается повышенной, что приводит $\mathrm{K}$ увеличению концентрации GSH и усиливает антиоксидантную защиту патологических клеток [9]. Соотношение 2GSH/ GSSG служит важным показателем редокс-состояния внутриклеточной среды, изменение которого связано не только с патологией, но и с регуляцией многих физиологических процессов, например дифференцировкой [10, 11], пролиферацией [12], апоптозом [13]. Однако именно масштабные и неконтролируемые изменения клеточного тиол-дисульфидного обмена приводят к серьезным заболеваниям, в том числе нейродегенеративным, а также связанным с отклонениями работы многих систем органов, в том числе иммунной, сердечно-сосудистой и рядом других [14]. Существуют и другие функции глутатиона в организме. Известно, что метаболизм различных ксенобиотиков включает в себя стадию конъюгации с GSH в реакции, катализируемой глутатионтрансферазами [15].

Определить GSH и GSSG в образце можно с помощью метода высокоэффективной жидкостной хроматографии (ВЭЖХХ). Другой подход исследования редокс-состояния пула глутатиона в биологических образцах основан на использовании химических красителей. Таким классическим красителем является реагент Эллмана [16], использование которого подразумевает разрушение клеток для получения клеточных экстрактов или гомогенатов тканей. Синтетические красители ThiolQuant Green [17] и RealThiol [18] позволяют проводить измерения в целостных клетках. Однако с помощью обоих «прижизненных красителей» можно оценить количественные изменения только GSH. В настоящее время наиболее популярным инструментом для исследования динамики соотношения 2GSH/GSSG служит семейство генетически кодируемых индикаторов на основе редокс-чувствительных флуоресцентных белков (roFP). Функционирование таких индикаторов основано на окислении двух поверхностных остатков цистеина, введенных в структуру флуоресцентного белка методом точечного мутагенеза. Степень окисления редоксчувствительных цистеиновых остатков биосенсора определяется окружающим пулом глутатиона. Остатки цистеина в структуре белка расположены близко друг к другу таким образом, что при окислении в ответ на изменение соотношения 2GSH/GSSG образуют дисульфидную связь. Образование такой связи в структуре белка приводит к конформационным изменениям, влияющим на его спектральные свойства. Таким образом, в зависимости от значения параметра 2GSH/GSSG roFP находится в окисленном или восстановленном состояниях, которые можно различить спектрально. Поскольку такой индикатор имеет белковую природу, его ген можно экспрессировать в исследуемой биологической системе любого уровня сложности: от отдельных клеточных органелл до тканей трансгенного организма. Первый представитель этого семейства индикаторов был создан на основе желтого флуоресцентного белка [19], позже появились белки на основе зеленого $[20,21]$. К настоящему моменту создана обширная коллекция редокс-чувствительных индикаторов для мониторинга динамики изменения соотношения 2GSH/ GSSG в живых системах в режиме реального времени. Существующие версии отличаются по многим своим параметрам, например, по спектральным характеристикам, редокс-потенциалу, скорости реакции, специсичности [22].

Индикаторы с красной эмиссией флуоресценции наиболее удобны для работы in vivo из-за минимального поглощения света данного диапазона длин волн соединениями, которые содержатся в тканях (вода, гемоглобин, меланин и др.). Кроме того, зеленый свет, который используется для возбуждения хромофора красного белка, менее токсичен для клеток по сравнению с синим и фиолетовым, которыми возбуждают флуоресценцию индикаторов на основе белков с зеленой эмиссией. Целью настоящей работы было получение новой версии редокс-чувствительного индикатора на основе красного флуоресцентного белка mKate2 [23]. Созданный нами индикатор roKate для регистрации изменения соотношения 2GSH/GSSG характеризуется повышенной рН-стабильностью и высокой яркостью. Особенностью биосенсора roKate является его необратимый ответ в клетках млекопитающих после окисления, что позволяет использовать его в качестве индикатора, обладающего «памятью окисления» пула глутатиона.

\section{МАТЕРИАЛЫ И МЕТОДЫ}

\section{Получение генетических конструкций}

С помощью направленного мутагенеза мы вносили точечные мутации в структуру красного флуоресцентного белка mKate2. Реакционная проба для амплификации ДНК содержала термостабильную полимеразу Tersus c соответствующим бусером (Evrogen; Россия), эквимолярную смесь dNTP (по 200 мкM), праймеры (10 мкМ) и матричную ДНК (100 нг). Программа ПЦР включала 22 цикла, каждый из которых включал стадию денатурации $\left(95^{\circ} \mathrm{C}, 30 \mathrm{c}\right)$, отжига праймеров $\left(60^{\circ} \mathrm{C}, 45 \mathrm{c}\right)$, элонгацию $\left(72^{\circ} \mathrm{C}, 90 \mathrm{c}\right)$.

Для улучшения свойств отобранных конструкций проводили случайный мутагенез. Реакционная проба содержала термостабильную полимеразу Taq с соответствующим буфером (Evrogen; Россия), праймеры (10 MKM), dATP (200 MKM), dTTP (200 мкM), dCTP (200 MKM), dGTP (360 мкM), MnSO4 (640 мкM), матричную ДНК (20 пг). Программа ПЦР включала 27 циклов, каждый из которых включал стадию денатурации (95 ${ }^{\circ} \mathrm{C}, 30$ c), отжига праймеров $\left(60^{\circ} \mathrm{C}, 45\right.$ c), элонгацию $\left(72^{\circ} \mathrm{C}, 105\right.$ c). Ожидаемое количество мутаций - 4-5 на конструкцию [24]. Полученные версии были клонированы в плазмидные векторы pQе30 (для экспрессии в бактериальных клетках) и рС1 (для экспрессии в клетках млекопитающих).

\section{Работа с бактериальной культурой клеток}

B работе использовали клетки E. coli штамма $\mathrm{XL}$ 1-Blue. Клетки растили в жидкой среде LB или на твердой среде на чашках Петри (1,5\% агар, приготовленный на LB). Среда содержала антибиотики: 100 мкг/мл ампициллин (в случае 
использования вектора pQе30) или 25 мкг/мл канамицин (в случае использования вектора рС1).

Для скрининга флуоресценции бактериальных клонов использовали флуоресцентный бинокуляр US SZX12 (Olympus; Япония). Отбирали наиболее яркие колонии, которые переносили на твердую среду. Для последующих измерений использовали спектрофлуориметр Varian Cary Eclipse (Agilent; США). Для этого биомассу бактерий суспендировали в 1 мл PBS буфера и регистрировали спектры эмиссии ( $\lambda$ ех $=585$ нм) и возбуждения флуоресценции $(\lambda e m=624$ нм). Для изменения редоксстатуса клеток к суспензии добавляли $\mathrm{H}_{2} \mathrm{O}_{2}$ до конечных концентраций 100 мкМ - 2 мМ. Полученные результаты обрабатывали в программе OriginPro 9.0 (OriginLab; США).

\section{Получение препарата рекомбинантного белка}

Для получения препарата рекомбинантного белка наращивали биомассу бактерий E. coli XL 1-Blue, экспрессирующих ген биосенсора. Для этого бактериальные клетки трансформировали плазмидой pQe30 roKate. Полученный в данной системе белок на С-конце содержит гистидиновый таг (His-tag). Полученные клоны бактерий помещали в среду LB c антибиотиком (ампициллин 100 МКГ/Мл), условия роста - 16 ч при комнатной температуре (перемешивание 200 об./мин). Полученную суспензию бактерий осаждали центрифугированием в течение 15 мин при $2000 \mathrm{~g}$ и температуре $4{ }^{\circ} \mathrm{C}$. Лизис клеток проводили с помощью коммерческого набора В-PER ${ }^{\mathrm{TM}}$ Bacterial Protein Extraction Reagent (ThermoFisher; CШA). Далее пробы центрифугировали в течение 20 мин при $18000 \mathrm{~g}$ и температуре $4{ }^{\circ} \mathrm{C}$. Надосадочную жидкость наносили на колонку, содержащую смолу TALON (Clontech; США), связывающую His-tag. Элюцию белка с колонки осуществляли раствором PBS (pH 7,0), содержащим 250 мМ имидазола. Для очистки рекомбинантного белка от имидазола использовали гель-фильтрационные колонки с сефадексом G-50 (GE Healthcare Life Sciences; Англия). Для восстановления дисульфидной связи белка пробу инкубировали 30 мин в растворе PBS c 20 мМ дитиотреитола.

\section{Тестирование биосенсора in vitro}

Аликвоту очищенного белка добавляли к 1 мл раствора PBS $(\mathrm{pH} 7,0)$ до конечной концентрации 100 нМ в кювете для спектрофотометрии. Спектры эмиссии и возбуждения фрлуоресценции регистрировали с помощью спектрофрлуориметра Varian Cary Eclipse (Agilent; США), параметры регистрации: $\lambda$ ex $=585 \mathrm{HM}, \lambda e m=624 \mathrm{HM} . \mathrm{K}$ пробе добавляли GSSG или GSH в диапазоне концентраций 50 мкM - 2 мМ, после чего регистрировали спектры.

Для определения редокс-потенциала биосенсора очищенный препарат белка титровали растворами глутатиона, в которых соотношение GSH/GSSG варьировало от 10 : 0 до 0 : 10. Для расчета редокс-потенциала использовали следующий подход. Определяли величину Y по формуле: $Y=\left(F_{n}-F_{\min }\right) /\left(F_{\max }-F_{n}\right)$, где $F_{n}-$ интенсивность флуоресценции в пробе с заданным соотношением GSH/ GSSG, $F_{\min }$ - интенсивность флуоресценции в пробе с 1 мМ GSSG, a $F_{\text {max }}$ - в пробе с 1 мM GSH. По полученным значениям строили график зависимости logY от log([GSSG]/ [GSH]). Находили соотношение GSSG/2GSH, при котором сигнал биосенсора изменялся на 50\%, найденное значение обозначали, как величину А. Константу равновесия $\mathrm{K}_{\text {eq }}$ определяли по формуле $\log \mathrm{K}_{\text {eq }}=\log \left(\mathrm{F}_{\max } / \mathrm{F}_{\min }\right)-\log \mathrm{A}$.
Рассчитывали редокс-потенциал (E) по формуле: $\mathrm{E}=\mathrm{E}_{0}-$

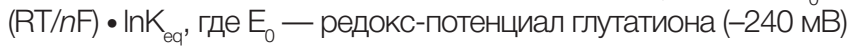
при $\mathrm{pH}$ 7,0, R - газовая постоянная (8,314 Дж/моль • K), Т - температура (K), n - число электронов, участвующих в обмене, F — константа Фарадея (96490 Дж/моль/В).

Для определения степени окисленности (OxD) пула глутатиона и roKate в пробе с определенным соотношением GSH : GSSG использовали следующие формулы:

$$
\begin{aligned}
& \mathrm{OxD} D_{\mathrm{GSH}}=2[\mathrm{GSH}] /(2[\mathrm{GSSG}]+[\mathrm{GSH}]), \\
& \mathrm{OxD}_{\text {rokate }}=[\mathrm{GSH}] /\left([\mathrm{GSSG}]\left(\mathrm{K}_{\text {eq }}+[\mathrm{GSH}] /[\mathrm{GSSG}]\right)\right) .
\end{aligned}
$$

Квантовый выход биосенсора рассчитывали по формуле: $\mathrm{QY}=\left(\left(\mathrm{Em}_{\text {roKate }} \cdot \mathrm{Abs_{ \text {mKate2 } }}\right) /\left(\mathrm{Em}_{\text {mKate2 }} \cdot \mathrm{Abs}_{\text {roKate }}\right)\right) \cdot \mathrm{QY}_{\text {mKate2 }}$, где $\mathrm{Em}_{\text {rokate }}$ и $\mathrm{Em}_{\text {mKate2 }}$ - интенсивность фрлуоресценции биосенсора roKate и белка сравнения mKate2 в максимуме эмиссии при $\lambda=624$ нм, Abs $_{\text {rokate }}$ и $\mathrm{Abs}_{\text {mkate2 }}$ - поглощение биосенсора roKate и белка сравнения mKate2 при $\lambda=590$ нм, $\mathrm{QY}_{\text {mKate2 }}$ - квантовый выход mKate2 (известная величина, равная 0,4).

Для оценки коэффициента молярной экстинкции (६) регистрировали спектр поглощения при $\lambda=590$ нм для нативного белка roKate и для белка, денатурированного в

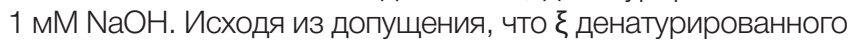
хромофрора roKate равен $\xi$ mKate2 (62500 $\left.\mathrm{M}^{-1} \cdot \mathrm{cm}^{-1}\right)$, рассчитывали коэффициент молярной экстинкции нативного roKate по следующей формуле: $\xi_{\text {нативного }}=\left(\mathrm{Abs}_{\text {нативного }}\right.$ • $\xi_{\text {денат }} . / \mathrm{Abs}_{\text {денат }}$

Для определения величины $\mathrm{pK}_{\mathrm{a}}$ биосенсора использовали ряд буферных растворов с заданным значением $\mathrm{pH}$ от 3,0 до 11,0 с шагом 0,5. Аликвоту белка добавляли в каждый из растворов до конечной концентрации 100 нМ и регистрировали спектр возбуждения фрлуоресценции, после чего строили график зависимости интенсивности от рН.

\section{Культура клеток млекопитающих}

В работе использовали клетки линии HeLa Kyoto, которые культивировали в среде DMEM с 10\% FBS, 2мМ глутамина, $1 \%$ антибиотиков пенициллина и стрептомицина. Условия содержания - $37^{\circ} \mathrm{C}, 5 \% \mathrm{CO}_{2}$.

Перед проведением трансфекции клетки культивировали на 35 мм чашках со стеклянным дном для микроскопии FluoroDishes (World Precision Instruments; США). Плазмидную ДНК смешивали с реагентом для трансфекции FuGene HD (Promega; США), следуя рекомендациям производителя. После добавления трансфекционного раствора в культуральную среду с клетками, флаконы с конечной смесью помещали в инкубатор. Микроскопию проводили на следующий день.

\section{Флуоресцентная микроскопия}

Для микроскопии клеток использовали флуоресцентный микроскоп DMl 6000 B (Leica; Германия), оборудованный ртутной лампой 120W HXP (Osram; Германия) в качестве источника света, и CCD-камерой CoolSNAP HQ (Photometrics; США). Для регистрации флуоресценции в диапазоне красной области света использовали фильтр TX2 (Excitation: BP560/40; Emission: ВР645/75). Перед микроскопией клеточную среду DMEM заменяли раствором Хэнкса, содержащим 15 мМ Hepes. Микроскопию проводили В 1 мл среды при температуре $37^{\circ} \mathrm{C}$. В качестве неспецифического окислителя внутриклеточного пула глутатиона использовали пероксид водорода, который 
добавляли к клеткам в объеме 100 мкл до конечной концентрации 750 мкМ. В качестве восстановителя использовали дитиотреитол до конечной концентрации 2 мМ. Полученные серии изображений анализировали с помощью программы Leica Application Suite Advanced Fluorescense (Leica; Германия). Конечную обработку результатов проводили с помощью программ ImageJ (EMBL; Германия) и OriginPro 9.0 (OriginLab; США).

\section{РЕЗУЛЬТАТЫ ИССЛЕДОВАНИЯ}

\section{Получение генетических конструкций}

Для создания редокс-биосенсора, позволяющего регистрировать изменение соотношения 2GSH/GSSG, мы выбрали красный флуоресцентный белок mKate2, который отличается высокой яркостью, повышенной $\mathrm{pH}-$ стабильностью в физиологическом диапазоне изменений, а также мономерным состоянием [23]. В структуру белка mKate2 с помощью направленного мутагенеза мы ввели пару остатков цистеина (Cуs) таким образом, чтобы при окислении они могли формировать дисульфидную связь. Нами было получено 10 версий белка, отличающихся позициями вставок Cуs: 142/198, 142/196, 141/161, 144/196, 141/198, 141/161, 141/196, 107/118, 140/214, 200/214. Известно, что равновесие между редокс-активными остатками цистеинов созданных ранее биосенсоров rхYFP, roGFP и пулом глутатиона устанавливается достаточно медленно. Однако если локально возле этих белков увеличить концентрацию глутаредоксина (Grx), реакция протекает значительно быстрее. По этой причине для увеличения динамических характеристик биосенсоров, rxYFP и roGFP были на уровне гена связаны с человеческим Grx1 через полипептидный линкер [25, 26]. Все полученные нами пробы на основе белка mKate2 также содержали на $\mathrm{N}$-конце человеческий Grx1, присоединенный с помощью линкера (Gly-Gly-Ser-Gly-Gly). На рис. 1А представлена схема функционирования предполагаемого биосенсора.

\section{roKate в бактериальной системе экспрессии}

Полученные нами генетические конструкции мы экспрессировали в бактериальных клетках E. coli штамма XL1 Blue. Через сутки у выросших клонов мы анализировали наличие фрлуоресценции и оценивали яркость. Для определения функциональной активности каждой светящейся версии биосенсора мы регистрировали изменение спектров возбуждения фрлуоресценции в суспензии бактерий до и после добавления пероксида водорода $\left(\mathrm{H}_{2} \mathrm{O}_{2}\right)$ до конечной концентрации $1 \mathrm{MM} . \mathrm{H}_{2} \mathrm{O}_{2}$ является сильным окислителем, который, в избытке попадая в клетку, значительно изменяет редокс-состояние внутренней среды, в том числе редокс-состояние пула глутатиона, сдвигая равновесие в сторону образования GSSG. B качестве отрицательного контроля в этой системе мы использовали белок Grx1-mKate2, не содержащий редокс-активных Cys в хромофорном окружении флуоресцентного белка и поэтому не демонстрирующий спектральных изменений в ответ на окисление. Среди всех вариантов для дальнейшей работы мы отобрали лишь две конструкции с Cуs в положениях 141/198 и 141/196. Другие мутантные формы белка были либо не флуоресцирующими, либо не реагировали на окисление.

Интенсивность флуоресценции отобранных мутантных форм в ответ на добавление $\mathrm{H}_{2} \mathrm{O}_{2}$ изменялась менее чем на 10\%. Для улучшения свойств белков мы провели цикл случайного мутагенеза с их генами. Данный метод подразумевает внесение в ген контролируемого количества случайных мутаций. С помощью такого подхода можно получить тысячи вариантов одного и того же белка, отличающихся несколькими аминокислотными заменами. При дальнейшем скрининге можно отобрать версии с оптимальными свойствами, поскольку даже единичная мутация может привести к значительным изменениям интересующих параметров белка. После проведения нескольких циклов случайного мутагенеза мы отбирали наиболее яркие клоны, которые в дальнейшем тестировали в условиях окислительного стресса. В результате была отобрана версия, которая, помимо редокс-активных Cys141 и Cys198, содержала две дополнительные мутации Lys12Glu и Asn21Asp в структуре флуоресцентного белка. Указанную мутантную форму белка назвали roKate. Амплитуда ответа roKate в бактериальных клетках при окислении составляет не менее 40\% (падение интенсивности флуоресценции).

\section{Определение характеристик roKate in vitro}

Для более детального исследования свойств полученной версии биосенсора мы выделили белок roKate. Для белка характерен один пик в спектре возбуждения фрлуоресценции с максимумом 585 нм и один пик эмиссии с максимумом в области 624 нм (рис. 1Б). Поскольку для первоначального скрининга мы использовали высокие концентрации $\mathrm{H}_{2} \mathrm{O}_{2}$, прежде всего мы проверили, может ли $\mathrm{H}_{2} \mathrm{O}_{2}$ напрямую окислять редокс-активные Суs остатки белка. Для этого в пробу с белком (100 нM) добавляли $\mathrm{H}_{2} \mathrm{O}_{2}$ до конечной концентрации 1 мМ, спектр возбуждения фллуоресценции такой пробы не изменялся (рис. 1В). Если к белку предварительно добавить восстановленный глутатион GSH (1 мM), а после в ту же пробу внести 1 мМ $\mathrm{H}_{2} \mathrm{O}_{2}$, интенсивность флуоресценции падает примерно на $40 \%$, что обусловлено окислением GSH (рис. 1Г). Такой же ответ мы регистрировали при добавлении к белку заранее окисленного глутатиона GSSG (1 мМ) (рис. 1Д). При этом данная реакция обратима в условиях in vitro. При внесении в эту же пробу фермента глутатионредуктазы (GR) и NADPH интенсивность флуоресценции белка возвращается практически к исходному значению (рис. 1Д). Таким образом, изменение флуоресцентного сигнала белка опосредовано изменением редокс-статуса глутатиона.

Для определения редокс-потенциала roKate выделенный белок титровали растворами с содержанием GSH и GSSG в разных соотношениях (от $10: 0$ до $0: 10$ ). На рис. 2A представлена зависимость степени окисленности roKate от степени окисленности глутатиона. По полученным данным мы определили редокс-потенциал биосенсора, который составил $-245 \mathrm{mB}$.

Используя стандартный ряд буферных растворов с заданным значением $\mathrm{pH}$, мы протестировали $\mathrm{pH}$ чувствительность белка. Хромофор флуоресцентных белков может находиться в протонированном и депротонированном состояниях, благодаря аминокислотному остатку тирозина в его составе. Поэтому интенсивность флуоресценции зависит от значения $\mathrm{pH}$. В экспериментальной системе важно учитывать, насколько изменяется фрлуоресцентный сигнал используемого биосенсора при изменениях $\mathrm{pH}$ в физиологическом диапазоне значений $(6,0-8,0)$. Мы определили, что рКа биосенсора roKate составляет 6,5. При 
A



Б

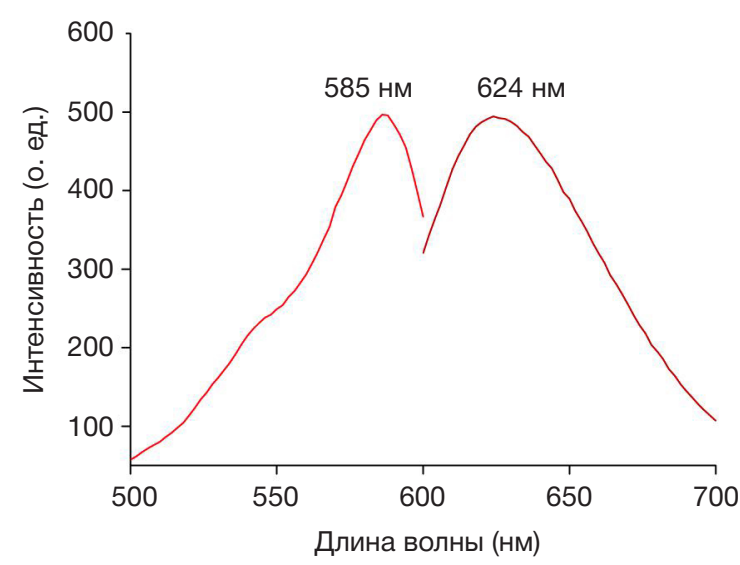

$\Gamma$

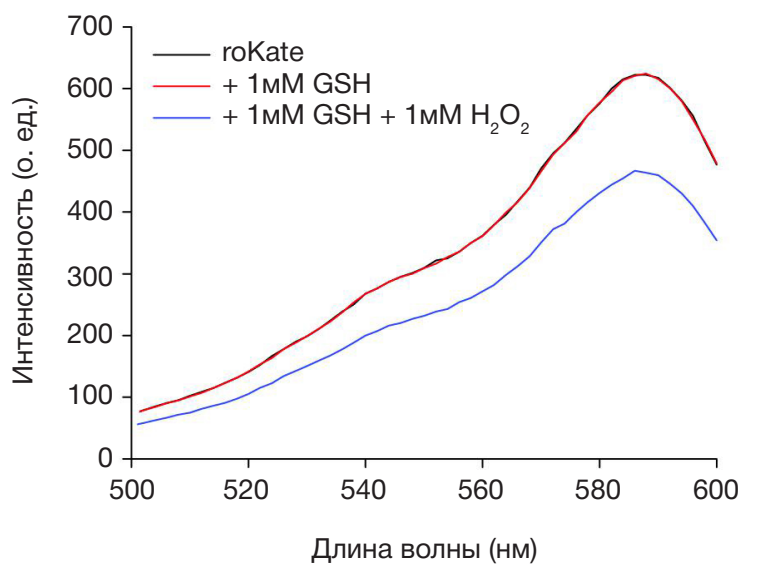

B

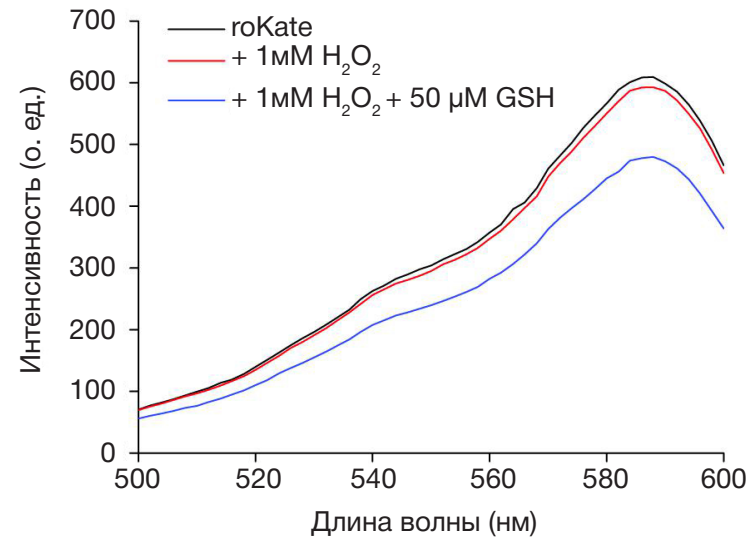

Д



Рис. 1. А. Схема функционирования биосенсора roКаtе. В структуру красного флуоресцентного белка внесены два близкорасположенных аминокислотных остатка цистеина, которые при участии человеческого глутаредоксина 1 (Grx1) формируют дисульфидную связь при окислении. При окислении уменьшается интенсивность флуоресценции белка. Б. Спектры возбуждения и эмиссии флуоресценции биосенсора roКаtе. В. Изменение спектра возбуждения флуоресценции roKate в ответ на добавление пероксида водорода и последующее добавление в ту же пробу GSH. Г. Изменение спектра возбуждения флуоресценции roKate в ответ на добавление GSH и последующее добавление в ту же пробу пероксида водорода. Д. Изменение спектра возбуждения флуоресценции roKate на выделенном препарате белка при окислении (добавка GSSG) и последующем восстановлении (ферментативная реакция восстановления глутатиона с участием GR и NADPH)

изменении рН от 6,0 до 8,0 интенсивность флууоресценции увеличивается примерно в 3 раза (рис. 2Б).

Мы также оценили коэффициент молярной экстинкции roKate и квантовый выход, которые составили $36400 \mathrm{M}^{-1}$ $\mathrm{cm}^{-1}$ и 0,3 соответственно.

\section{roKate в эукариотической системе экспрессии}

Ген roKate был перенесен в вектор pC1 для тестирования сенсора в клетках млекопитающих. В человеческих клетках линии HeLa Kyoto максимальная амплитуда ответа составила 55\% при окислительном стрессе, вызванном добавлением в среду $\mathrm{H}_{2} \mathrm{O}_{2}$ (максимальная концентрация 750 мкМ) (рис. ЗА и Б). Повторное внесение $\mathrm{H}_{2} \mathrm{O}_{2}$ осуществляли с целью выяснить максимальное изменение сигнала при окислении. Подобные биосенсоры в живых клетках обычно восстанавливаются клеточными системами без внесения каких-либо восстановителей. Однако roKate не восстанавливался в цитоплазме клеток HeLa Kyoto даже после инкубации с различными восстановителями (дитиотреитол, $\beta$-меркаптоэтанол, трис(2-карбоксиэтил) фосфин). Конструкция без Grx1 на N-конце значительно уступает полноразмерному биосенсору в скорости реакции (рис. ЗА). Данный факт свидетельствует в пользу того, что Grx1 выполняет ключевую роль в установлении равновесия между внутриклеточным пулом глутатиона и редокс-активными остатками цистеина сенсора. Версия без редокс-активных остатков Суs в структуре mKate2 в данной системе не продемонстрировала изменений флуоресцентного сигнала.

В эукариотической системе биосенсор roKate окисляется необратимо. Таким образом, roKate позволяет детектировать в клетках млекопитающих только динамику окисления пула глутатиона и не позволяет визуализировать его обратного восстановления. 
A



Б

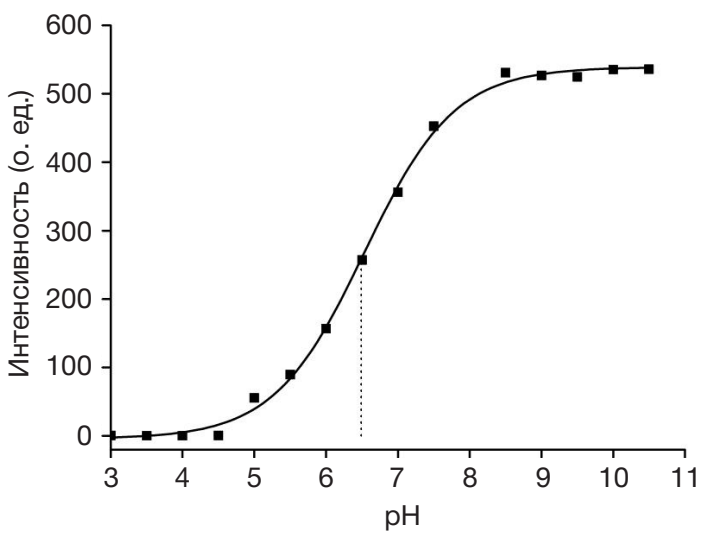

Рис. 2. А. Зависимость степени окисленности roКаtе от степени окисленности глутатиона. Б. Зависимость интенсивности флуоресценции гоКате от рН

A

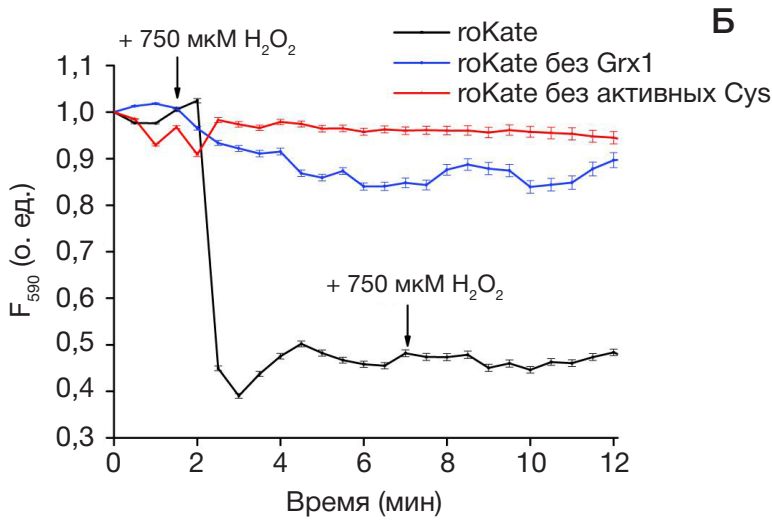

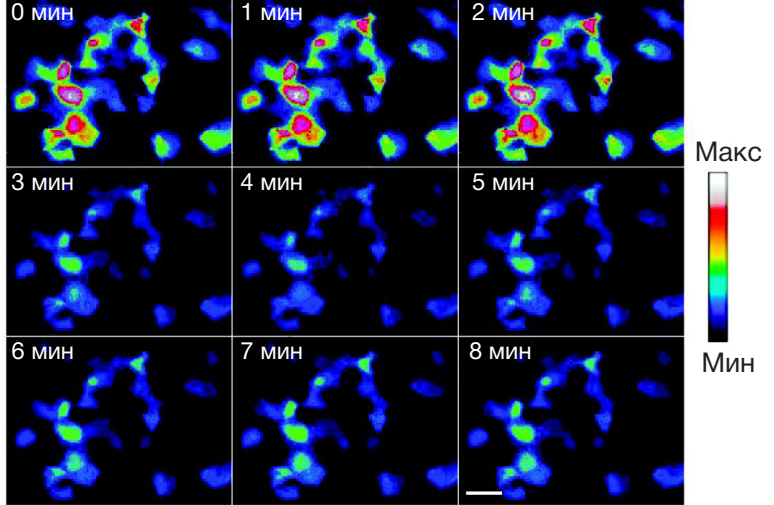

Рис. 3. Биосенсор roKate в клетках линии HeLa Kyoto. А. Динамика изменения интенсивности флуоресценции roКаte (черная линия), версии сенсора без Grx1 (синяя линия) и версии сенсора без редокс-активных остатков цистеина (красная линия) в цитоплазме живых клеток НеLa Куоto в ответ на внесение в среду пероксида водорода (момент добавки отмечен стрелкой). Планки погрешностей соответствуют стандартной ошибке среднего значения. Б. Фотографии клеток HeLa Kyoto, экспрессирующих биосенсор roKate, до и после добавки пероксида водорода (указанное время соответствует таковому на графике рисунка (A). Фотографии окрашены в псевдоцвета, соответствующие значению сигнала биосенсора. Шкала 40 мкм

\section{ОБСУЖДЕНИЕ РЕЗУЛЬТАТОВ}

Мы разработали генетически кодируемый фрлуоресцентный биосенсор для регистрации редокс-состояния пула глутатиона на базе красного фрлуоресцентного белка mKate2. Полученный нами биосенсор roKate отличается по свойствам и дизайну строения от ранее разработанного варианта rxRFP [27]. Индикатор rxRFP был создан на базе кругового пермутанта красного белка cpmApple. Круговые пермутанты фллуоресцентных белков получают путем соединения на уровне гена исходных N- и C-концов полипептидным линкером и формирования новых в непосредственной близости с хромофором. Таким образом структура кругового пермутанта флуоресцентного белка становится более конформационно подвижной, что влияет на изменение спектральных характеристик. В структуре биосенсора rxRFP редокс-активные остатки цистеина расположены на N- и C-концах кругового пермутанта, при этом белок не сшит с Grx [27], т. е. для его уравновешивания c окружающим редокс-состоянием пула глутатиона используется эндогенный Grx. Кроме того, хромофор круговых пермутантов фллуоресцентных белков более открыт для окружающей среды по сравнению с закрытыми структурами нативных белков. По этой причине, например, биосенсор rxRFP чувствителен к физиологическим колебаниям $\mathrm{pH}$.

Еще одним представителем семейства биосенсоров на основе красных фрлуоресцентных белков для регистрации соотношения 2GSH/GSSG является Grx1roCherry. Структура биосенсора Grx1-roCherry устроена по классическому принципу и состоит из белка mCherry, содержащего пару редокс-активных цистеинов, и соединенного через полипептидный линкер Grx1. Данный биосенсор отличается от roKate редокс-потенциалом (-311 мB), а также способностью к обратному восстановлению в различных клетках млекопитающих [28].

Помимо того, что биосенсоры с красной фрлуоресценцией более удобны для работы с системами in vivo, они могут быть использованы в комбинации с зелеными индикаторами в режиме многопараметрической микроскопии. Данный подход более информативен, поскольку позволяет регистрировать сразу несколько параметров в пределах одной биологической системы или один и тот же параметр, например, в разных компартментах клетки [29].

По неустановленной причине окисленный сенсор roKate в клетках млекопитающих не восстанавливается, поэтому он может быть использован в качестве «сенсора-памяти», фиксирующего момент окисления в живых клетках или тканях. Это может быть удобно в моделях с наличием длительных временных интервалов между биологическими событиями и регистрацией флуоресцентного сигнала, например при длительной пробоподготовке. За время, которое в некоторых случаях требуется для подготовки проб к анализу, восстановительные системы клеток могут восстановить пул глутатиона и исказить результат исследования. Поскольку roKate в клетках млекопитающих окисляется необратимо, эффект окисления глутатиона, вызванный различными воздействиями, может быть таким образом зафиксирован. Кроме того, биосенсор roKate также можно использовать для регистрации динамики 
окисления внутриклеточного пула глутатиона в режиме реального времени.

\section{ВЫВОДЫ}

Мы разработали новый генетически кодируемый красный флуоресцентный биосенсор roKate для регистрации редокс-состояния пула глутатиона. Биосенсор roKate может быть использован для изучения редокс-процессов, связанных с изменением соотношения 2GSH/GSSG в клетках бактерий. В клетках млекопитающих roKate окисляется необратимо. Данное свойство позволяет использовать roKate в качестве "сенсора-памяти", помогающего фиксировать во времени окисление пула глутатиона.

\section{Литература}

1. Lushchak VI. Glutathione homeostasis and functions: potential targets for medical interventions. J Amino Acids. 2012; 2012 736837.

2. Couto N, Wood J, Barber J. The role of glutathione reductase and related enzymes on cellular redox homoeostasis network. Free Radic Biol Med. 2016; (95): 27-42.

3. Nagy P. Kinetics and mechanisms of thiol-disulfide exchange covering direct substitution and thiol oxidation-mediated pathways. Antioxid Redox Signal. 2013; 18 (13): 1623-41.

4. Bekris LM, Shephard C, Janer M, Graham J, McNeney B, Shin J, Zarghami M, Griffith W, Farin F, Kavanagh TJ, Lernmark A. Glutamate cysteine ligase catalytic subunit promoter polymorphisms and associations with type 1 diabetes age-at-onset and GAD65 autoantibody levels. Exp Clin Endocrinol Diabetes. 2007; 115 (4) 221-28.

5. Polonikov AV, Ivanov VP, Solodilova MA, Khoroshaya IV, Kozhuhov MA Panfilov VI. The relationship between polymorphisms in the glutamate cysteine ligase gene and asthma susceptibility. Respir Med. 2007; 101 (11): 2422-4.

6. Tosic M, Ott J, Barral S, Bovet P, Deppen P, Gheorghita F, Matthey ML, Parnas J, Preisig M, Saraga M, Solida A, Timm S, Wang AG, Werge T, Cuenod M, Do KQ. Schizophrenia and oxidative stress: glutamate cysteine ligase modifier as a susceptibility gene. Am $J$ Hum Genet. 2006; 79 (3): 586-92.

7. Ramos PS, Oates JC, Kamen DL, Williams AH, Gaffney PM, Kelly JA et al. Variable association of reactive intermediate genes with systemic lupus erythematosus in populations with different African ancestry. J Rheumatol. 2013; 40 (6): 842-9.

8. Kamerbeek NM, van Zwieten R, de Boer M, Morren G, Vuil H, Bannink $\mathrm{N}$, et al. Molecular basis of glutathione reductase deficiency in human blood cells. Blood. 2007; 109 (8): 3560-6.

9. Backos DS, Franklin CC, Reigan P. The role of glutathione in brain tumor drug resistance. Biochem Pharmacol. 2012; 83 (8): 1005-12.

10. Huh YJ, Kim JM, Kim H, Song H, So H, Lee SY, et al. Regulation of osteoclast differentiation by the redox-dependent modulation of nuclear import of transcription factors. Cell Death Differ. 2006; 13 (7): 1138-46.

11. Kim JM, Kim H, Kwon SB, Lee SY, Chung SC, Jeong DW, et al. Intracellular glutathione status regulates mouse bone marrow monocyte-derived macrophage differentiation and phagocytic activity. Biochem Biophys Res Commun. 2004; 325 (1): 101-8.

12. Suthanthiran M, Anderson ME, Sharma VK, Meister A. Glutathione regulates activation-dependent DNA synthesis in highly purified normal human $T$ lymphocytes stimulated via the CD2 and CD3 antigens. Proc Natl Acad Sci USA. 1990; 87 (9): 3343-7.

13. Garcia-Ruiz C, Fernandez-Checa JC. Redox regulation of hepatocyte apoptosis. J Gastroenterol Hepatol. 2007; (22 Suppl 1): 38-42.

14. Ballatori N, Krance SM, Notenboom S, Shi S, Tieu K, Hammond CL.
Glutathione dysregulation and the etiology and progression of human diseases. Biol Chem. 2009; 390 (3): 191-214.

15. Armstrong RN. Glutathione S-transferases: reaction mechanism, structure, and function. Chem Res Toxicol. 1991; 4 (2): 131-40.

16. Sedlak J, Lindsay RH. Estimation of total, protein-bound, and nonprotein sulfhydryl groups in tissue with Ellman's reagent. Anal Biochem. 1968; 25 (1): 192-205.

17. Jiang X, Yu Y, Chen J, Zhao M, Chen H, Song X, et al. Quantitative imaging of glutathione in live cells using a reversible reactionbased ratiometric fluorescent probe. ACS Chem Biol. 2015; 10 (3): 864-74

18. Jiang X, Chen J, Bajic A, Zhang C, Song X, Carroll SL, et al. Quantitative real-time imaging of glutathione. Nat Commun. 2017; (8): 16087

19. Ostergaard H, Henriksen A, Hansen FG, Winther JR. Shedding light on disulfide bond formation: engineering a redox switch in green fluorescent protein. EMBO J. 2001; 20 (21): 5853-62.

20. Hanson GT, Aggeler R, Oglesbee D, Cannon M, Capaldi RA, Tsien RY, et al. Investigating mitochondrial redox potential with redoxsensitive green fluorescent protein indicators. J Biol Chem. 2004; 279 (13): 13044-53

21. Dooley CT, Dore TM, Hanson GT, Jackson WC, Remington SJ, Tsien RY. Imaging dynamic redox changes in mammalian cells with green fluorescent protein indicators. J Biol Chem. 2004; 279 (21): 22284-93

22. Schwarzlander M, Dick TP, Meyer AJ, Morgan B. Dissecting Redox Biology Using Fluorescent Protein Sensors. Antioxid Redox Signal. 2016; 24 (13): 680-712.

23. Shcherbo D, Murphy CS, Ermakova GV, Solovieva EA, Chepurnykh TV, Shcheglov AS, et al. Far-red fluorescent tags for protein imaging in living tissues. Biochem J. 2009; 418 (3): 567-74.

24. Доступно по ссылке: www.clontech.com, протокол № РТ3393-1.

25. Bjornberg $\mathrm{O}$, Ostergaard $\mathrm{H}$, Winther JR. Mechanistic insight provided by glutaredoxin within a fusion to redox-sensitive yellow fluorescent protein. Biochemistry. 2006; 45 (7): 2362-71.

26. Gutscher M, Pauleau AL, Marty L, Brach T, Wabnitz GH, Samstag Y, et al. Real-time imaging of the intracellular glutathione redox potential. Nat Methods. 2008; 5 (6): 553-9.

27. Fan $\mathrm{Y}$, Chen Z, Ai HW. Monitoring redox dynamics in living cells with a redox-sensitive red fluorescent protein. Anal Chem. 2015; 87 (5): 2802-10.

28. Shokhina AG, Kostyuk Al, Ermakova YG, Panova AS, Staroverov DB, Egorov ES, et al. Red fluorescent redox-sensitive biosensor Grx1roCherry. Redox Biol. 2019; (21): 101071.

29. Kostyuk Al, Panova AS, Bilan DS, Belousov W. Redox biosensors in a context of multiparameter imaging. Free Radic Biol Med. 2018; (128): 23-39.

Radic Biol Med. 2016; (95): 27-42

3. Nagy P. Kinetics and mechanisms of thiol-disulfide exchange covering direct substitution and thiol oxidation-mediated pathways. Antioxid Redox Signal. 2013; 18 (13): 1623-41.

4. Bekris LM, Shephard C, Janer M, Graham J, McNeney B, Shin J, 
Zarghami M, Griffith W, Farin F, Kavanagh TJ, Lernmark A. Glutamate cysteine ligase catalytic subunit promoter polymorphisms and associations with type 1 diabetes age-at-onset and GAD65 autoantibody levels. Exp Clin Endocrinol Diabetes. 2007; 115 (4): 221-28.

5. Polonikov AV, Ivanov VP, Solodilova MA, Khoroshaya IV, Kozhuhov MA, Panfilov VI. The relationship between polymorphisms in the glutamate cysteine ligase gene and asthma susceptibility. Respir Med. 2007; 101 (11): 2422-4.

6. Tosic M, Ott J, Barral S, Bovet P, Deppen P, Gheorghita F, Matthey ML, Parnas J, Preisig M, Saraga M, Solida A, Timm S, Wang AG, Werge T, Cuenod M, Do KQ. Schizophrenia and oxidative stress: glutamate cysteine ligase modifier as a susceptibility gene. Am J Hum Genet. 2006; 79 (3): 586-92.

7. Ramos PS, Oates JC, Kamen DL, Williams AH, Gaffney PM, Kelly JA, et al. Variable association of reactive intermediate genes with systemic lupus erythematosus in populations with different African ancestry. J Rheumatol. 2013; 40 (6): 842-9.

8. Kamerbeek NM, van Zwieten R, de Boer M, Morren G, Vuil H, Bannink $\mathrm{N}$, et al. Molecular basis of glutathione reductase deficiency in human blood cells. Blood. 2007; 109 (8): 3560-6.

9. Backos DS, Franklin CC, Reigan P. The role of glutathione in brain tumor drug resistance. Biochem Pharmacol. 2012; 83 (8): 1005-12.

10. Huh YJ, Kim JM, Kim H, Song H, So H, Lee SY, et al. Regulation of osteoclast differentiation by the redox-dependent modulation of nuclear import of transcription factors. Cell Death Differ. 2006; 13 (7): 1138-46.

11. Kim JM, Kim H, Kwon SB, Lee SY, Chung SC, Jeong DW, et al. Intracellular glutathione status regulates mouse bone marrow monocyte-derived macrophage differentiation and phagocytic activity. Biochem Biophys Res Commun. 2004; 325 (1): 101-8.

12. Suthanthiran M, Anderson ME, Sharma VK, Meister A. Glutathione regulates activation-dependent DNA synthesis in highly purified normal human $T$ lymphocytes stimulated via the CD2 and CD3 antigens. Proc Natl Acad Sci USA. 1990; 87 (9): 3343-7.

13. Garcia-Ruiz C, Fernandez-Checa JC. Redox regulation of hepatocyte apoptosis. J Gastroenterol Hepatol. 2007; (22 Suppl 1): 38-42.

14. Ballatori N, Krance SM, Notenboom S, Shi S, Tieu K, Hammond CL. Glutathione dysregulation and the etiology and progression of human diseases. Biol Chem. 2009; 390 (3): 191-214.

15. Armstrong RN. Glutathione S-transferases: reaction mechanism, structure, and function. Chem Res Toxicol. 1991; 4 (2): 131-40.

16. Sedlak J, Lindsay RH. Estimation of total, protein-bound, and nonprotein sulfhydryl groups in tissue with Ellman's reagent. Anal Biochem. 1968; 25 (1): 192-205.

17. Jiang $X, Y u$, Chen J, Zhao M, Chen $\mathrm{H}$, Song $X$, et al. Quantitative imaging of glutathione in live cells using a reversible reactionbased ratiometric fluorescent probe. ACS Chem Biol. 2015; 10 (3): 864-74.

18. Jiang X, Chen J, Bajic A, Zhang C, Song X, Carroll SL, et al. Quantitative real-time imaging of glutathione. Nat Commun. 2017; (8): 16087.

19. Ostergaard H, Henriksen A, Hansen FG, Winther JR. Shedding light on disulfide bond formation: engineering a redox switch in green fluorescent protein. EMBO J. 2001; 20 (21): 5853-62.

20. Hanson GT, Aggeler R, Oglesbee D, Cannon M, Capaldi RA, Tsien RY, et al. Investigating mitochondrial redox potential with redoxsensitive green fluorescent protein indicators. J Biol Chem. 2004; 279 (13): 13044-53.

21. Dooley CT, Dore TM, Hanson GT, Jackson WC, Remington SJ, Tsien RY. Imaging dynamic redox changes in mammalian cells with green fluorescent protein indicators. J Biol Chem. 2004; 279 (21): 22284-93.

22. Schwarzlander M, Dick TP, Meyer AJ, Morgan B. Dissecting Redox Biology Using Fluorescent Protein Sensors. Antioxid Redox Signal. 2016; 24 (13): 680-712.

23. Shcherbo D, Murphy CS, Ermakova GV, Solovieva EA, Chepurnykh TV, Shcheglov AS, et al. Far-red fluorescent tags for protein imaging in living tissues. Biochem J. 2009; 418 (3): 567-74.

24. Available from: www.clontech.com, протокол № РТ3393-1.

25. Bjornberg $\mathrm{O}$, Ostergaard $\mathrm{H}$, Winther JR. Mechanistic insight provided by glutaredoxin within a fusion to redox-sensitive yellow fluorescent protein. Biochemistry. 2006; 45 (7): 2362-71.

26. Gutscher M, Pauleau AL, Marty L, Brach T, Wabnitz GH, Samstag Y, et al. Real-time imaging of the intracellular glutathione redox potential. Nat Methods. 2008; 5 (6): 553-9.

27. Fan $Y$, Chen $Z$, Ai HW. Monitoring redox dynamics in living cells with a redox-sensitive red fluorescent protein. Anal Chem. 2015; 87 (5): 2802-10.

28. Shokhina AG, Kostyuk Al, Ermakova YG, Panova AS, Staroverov DB, Egorov ES, et al. Red fluorescent redox-sensitive biosensor Grx1roCherry. Redox Biol. 2019; (21): 101071.

29. Kostyuk Al, Panova AS, Bilan DS, Belousov W. Redox biosensors in a context of multiparameter imaging. Free Radic Biol Med. 2018; (128): 23-39. 